\title{
The future of pastoral farming in a changing climate
}

\author{
J. A. PALMER \\ Ministry of Agriculture and Forestry, PO Box 2526, Wellington \\ James.Palmer@maf.govt.nz
}

Pastoral farming in New Zealand has always been a dynamic and uncertain business. Climatic conditions, market forces and the regulatory environment confronting pastoral farmers each have a long history of change, often rapidly and markedly. It is not surprising then that pastoral farmers are a resilient bunch. It is also not surprising that in respect of anthropogenic climate change some farmers are sceptical of what they see as another passing fashion in science, public policy and environmentalism - change to be weathered.

This paper will not seek to make the case for anthropogenic climate change, but rather will focus on forecasts derived from the assessments of the Intergovernmental Panel on Climate Change, and what is being done or not done in response to these forecasts in New Zealand by industry and government alike.

Running a business where operating variables are as unpredictable as they are for pastoral farmers is a Herculean challenge, but unfortunately it appears that the three major variables of climate, markets and regulation are set to remain, and in all probability increase, in dynamism and unpredictability.

On the first and most worrying front is the physical impact of climate change. While we expect there will be no strong increase or decrease during the coming century in pastoral production when averaged over the whole country, it is the impact of extreme weather events in specific regions that is of particular concern.

What makes this increase in weather variability doubly worrying is that because the change doesn't appear large when averaged across a sector land managers may underestimate the need to change, leading to complacency and under-investment in infrastructure, resources and research. In some eastern regions even average year decreases in production are expected, which may decrease the overall country's resilience to withstand extreme events.

Last year a group of national experts, EcoClimate, published 'Costs and Benefits of Climate Change and Adaptation to Climate Change in New Zealand Agriculture: What Do We Know so Far?' for the Ministry of Agriculture and Forestry (http://www.maf. govt.nz/climatechange/slm/ag-production/). This study was an early attempt at putting some shape around our understanding of future sensitivities of agricultural production to changes in rainfall and temperature. While not a predictor of what lies ahead for pastoral farming the report did conclude that:

- Agricultural areas in eastern New Zealand are likely to face greater shortages of water in future. This includes Northland, Hawkes Bay, Canterbury and parts of the Tasman and Marlborough regions.

- A decline is projected for dairy and sheep/beef production in an average-year and worst-year production in the east coast (Bay of Plenty, Gisborne, Hawkes Bay, Wellington, Canterbury), and also for Northland.

- Under the model used the projected driest years in 2030 and 2080 reach only $52 \%$ and $50 \%$ of the longterm average production for dairy and sheep/beef, respectively.

As the century progresses, the drying of pasture in spring is likely to begin earlier; the projected increase in temperatures and growing degree days may give rise to an earlier start to pasture growth in the late winter or spring. Farmers might choose to bring forward some of their operations in response to the changes, for instance, lambs may be ready for the works earlier than at present.

Water supply reliability from irrigation systems fed from the Southern Alps source may increase. But it is yet unclear whether the increased water supply will compensate for an increase in demand.

Improvements in production are projected for both dairy and sheep/beef in the West Coast and Southland. These regions are likely to remain wetter with a warming climate.

Increased atmospheric $\mathrm{CO}_{2}$ will, in the short to medium term, increase forage growth and may in turn increase water-use efficiency where higher levels of evapo-transpiration do not cancel out any gains. This is one example of the complex set of interdependencies and feedback loops around the climate systems relationship to the biosphere that makes clearly anticipating the future outlook for farming so very fraught.

However, despite this uncertainty there is much that can and is being done. Adaptation to climate change, particularly dry land farming, has been a major focus 
in Australia in recent years but is also being advanced in New Zealand, with a range of community projects funded by MAF's Sustainable Farming Fund. There are also a wide range of research projects completed or underway that has been funded from MAF's Sustainable Land Management and Climate Change Plan of Action. These studies and projects are providing a strong information platform for land managers to adapt and prepare for a changing climate.

Other pastoral industry participants are looking at technology fixes. Research by the Pastoral Genomics Consortium is seeking to develop a commercially available drought tolerant ryegrass, through the use of genetic modification technology. This forage has yet to be put through the Environmental Risk Management Authority's processes for field trialling and release but can be expected to generate much public debate. The nature of a forage crop and the associated production systems mean that containment of a GM ryegrass variety will be exceptionally difficult. We can expect that there will be debate about whether such technology should be employed to allow farmers to continue farming in ways similar to previous, more stable climate conditions, or whether in the long-run a completely different approach to farming dry land areas is more sustainable.

Increased frequency of adverse events will encourage the further development of risk management measures, which may in some cases see a reduction in the intensification of pastoral farming we have seen in recent years. The Waikato drought of 2008 showed how intensive farming systems can be more vulnerable. This drought highlighted the growing interdependence between farmers and different regions for feed supply. If a more variable fed supply is to become commonplace then farmers will need more resilient and reliable systems that could be expected to see a migration from individual procurement of feed on 'spot' markets to contracting supply where risk is shared between the grower and buyer.

Even fairly basic issues such as weed control are expected to become more complicated under a fast changing climate. In the US, studies show that weed growth is expected to accelerate but in some cases the effectiveness of herbicides, like glyphosate, to reduce. In New Zealand, we can expect pests and weeds to respond to climate change differently, further adding to the complexity and interdependencies discussed above. Similarly climatic pressure can be expected to require greater pastoral renewal but reduce cash flow to support the planting of new pasture. A greater focus on the quality and resilience of pasture species and weed management can be expected as pastoral farmers struggle to maintain production in a more variable and often drier climate.
Increased extreme weather events will have a flow on effect on existing infrastructure. The need for increased investment in better infrastructure to safeguard the resilience of communities and agriculture production systems might become more pressing. Increased high intensity rainfall will affect flood and drainage infrastructure that when overwhelmed will inundate pasture more frequently. On farm this will be particularly important for pastoral farmers who seek to minimise risk to their businesses in anticipation of climate change.

In eastern areas, where increased frequency and severity of drought conditions are projected, irrigation infrastructure will be critical to support increased production. The efficiency of existing irrigation offers real scope to get more from less, and more water harvesting and storage infrastructure will be important too. Again the balance of risk will need to be considered between the large capital costs of water storage and whether it can be recouped from production or will result in stranded assets, or instead whether it makes more sense to change farming practices altogether to better adapt to permanently drier conditions.

While changes have been occurring on the farm, government has also been working to develop a workable policy response. To date the regulatory response to climate change has been a drawn out and continually evolving area of endeavour. New Zealand has wrestled with the stark reality of agriculture's contribution to the nation's emission liabilities and the dependence of the country's wellbeing on a biologically based economy. As we know, liabilities for New Zealand's growth in pastoral emissions over 1990 levels lie with taxpayers for the first commitment period from 2008 to 2012 . What lies beyond 2012 is less clear.

The global food security imperative and the major contribution of agriculture to developing countries' emission profiles suggest that agricultural emissions may yet get favourable treatment from the United Nations Framework Convention on Climate Change (UNFCCC) process. The difficult balancing act for the global community is agriculture's significant contribution to global greenhouse gases on the one hand, and yet the world can ill afford to produce less food, and needs to create an agreement that developing countries can live with.

Overall the landscape suggests we can expect an ongoing global regulatory response that seeks to encourage efficient and lower GHG intensive food production, while avoiding discouraging food production outright. In this respect some kind of 'intensity-based' approach within global agreements is possible.

For extensive farming on land perhaps better suited 
to forestry it will be a continuing challenge to convince the world that such land resources are best suited to producing beef and lamb for wealthy palates rather than for locking up carbon. Even our more intensive production systems will not be immune from debates about diet, as explored further below. It is inevitable that changing conditions, whether they be physical, market or regulation driven, will continue to impact on the economics of pastoral farming and in turn land values. Some land-use change in response to the physical, market and regulatory conditions resulting from a changing climate is inevitable.

The markets that receive our export produce are changing too and in the last few years interest has been developing toward 'carbon foot printing' of products and a debate has been growing about the 'food miles' products travel to consumers' plates. 'Buy local' campaigns and gimmicks such as the ' 100 mile diet' have been capturing public attention, placing a spotlight on the distance produce from New Zealand typically travels to market. Major international retail chains have been following and in some cases leading this trend using 'sustainability' issues to either position themselves relative to competitors (e.g. Marks and Spencers) or use information to drive efficiency and cost reductions in their own supply chains (e.g. Walmart).

Fortunately, New Zealand producers have been on the front foot and under MAF's Greenhouse Gas Foot printing Strategy, are ahead of the game by undertaking high quality life cycle assessments that give overseas retailers and consumers the information they seek. The initiative has also helped identify areas where focus is required to reduce emissions and increase efficiencies. Work to date suggests shipping remains an area of risk for New Zealand and more work is needed to find strategies to reduce emissions from this part of the supply chain.

Water footprints are now growing in international focus as well. As New Zealand producers seek to increase their productivity and manage climate risk with water storage and irrigation the 'size' of their water footprints are also likely to grow. This, as well as looming institutional frameworks designed to better ration water use and improve water quality, will see a greater push toward water use efficiency and more careful management. The commercial upside for New Zealand in this area is that being surrounded by oceans, we can expect to continue with high levels of regular rainfall, while many of our continental competitors will see more intermittent rainfall and require greater water storage and irrigation to replace rainfall, increases costs of production.

Discussion and concern is not only quarantined to how food is produced, but also what people eat. Diet is already a major focus in developed economies owing to the obesity epidemic, and has long been the subject of consumer concern in relation to the fast food industry. In the eyes of consumers the relationship of food consumption to climate change is a newer phenomenon but combined with broader environmental and economic concerns there are the ingredients here for a 'perfect storm'. Already eating less meat is being singled out by many climate campaigners and scientists as a practical step for consumers to take to reduce their own footprints. Looking ahead producers of animal protein the world over will need to address these concerns.

So as far into the future as MAF can see right now New Zealand pastoral farmers will need to have a focus on climate change issues and the emissions of their production systems. This is an inescapable reality that also comes with business opportunities. The currently proposed Emissions Trading Scheme provides a relatively soft landing for agriculture from 2015 onward, with heavy levels of support from taxpayers. How this is implemented will be in part be determined by the pastoral sectors engagement and influence over the implementation of the system.

A farm-level point of obligation for emissions liabilities and reductions has much to commend to it as it ensures that market signals are directed to those best placed to respond and ensures incentives on farm for managing production toward lower emissions. But without a low cost and reliable way to calculate onfarm emissions the compliance costs and complexity are simply too high and a processor level point of obligation remains the sensible short to medium term solution.

To date farming leaders have resisted the National Animal Identification and Traceability system to be used for monitoring stock for emissions purposes. If the sector can see past this resistance and see the benefit of bundling traceability for retailers and consumers with biosecurity information, emissions profiles and potentially productivity data, then New Zealand pastoral farmers could have a world leading system on farm-level information. This could position our pastoral farmers exceptionally well in providing markets with high levels of information about stock and their production life cycle, but at present this is a long way from the comfort zone of pastoral farming leaders.

Resistance to taking action to reduce greenhouse gas emissions from pastoral farming has also been driven by the limited existence of mitigation technologies. It is not necessary to dwell here on the extensive programme of research being funded by the government and the Pastoral Greenhouse Gas Research Consortium, which is well known, suffice to say that in the longerterm scientific breakthroughs to dramatically reduce 
ruminant methane emissions seem promising. On the nitrogen side inhibitors look promising as well and new joint MAF/Industry three year study into their effectiveness is underway.

The co-benefits for water quality from reduced loss of nitrogen from pasture and better effluent management underscores the potential for science on pastoral emissions to drive a more systems based approach to farming. Similarly, the focus on emissions across the supply chain enhances the focus on overall efficiency and connectivity between supply chain partners. All of this is about information that can drive better quality decision-making, support higher production efficiency, lower input costs, achieve greater resilience and ultimately a better value proposition for end consumers.

Climate change is but one dynamic factor affecting pastoral farmers. Market and regulatory drivers are also demanding more information and better natural resource use and management. Essentially physical, market and regulatory drivers may push pastoral farmers toward more 'closed systems' whereby production is less reliant on external inputs and thereby more sustainable, and where producers are connected to consumers in a feedback loop of information transfer that generates trust and value.

The message throughout this paper is that physical, market and regulatory change is forecast to continue and most probably increase for pastoral farmers. They will face a more complex operating environment and more of a systems approach to pastoral farming will be required with the skills, human capability and knowledge transfer system to support it. Undoubtedly greater cooperation and partnership between land managers and greater levels of investment in technology, information collection and sensing, and in risk management will be needed. This is a big challenge for pastoral farmers but their long history of innovation and resilience should position them well. 